\title{
Prediction of Birth Weight at Term: Validation of a Clinical Method in a Low Resource Setting
}

\author{
Cajethan Ife Emechebe ${ }^{1, *}$, Charles Obinna Njoku ${ }^{1}$, Jenkins Tobechukwu Ukaga ${ }^{1}$, \\ Edu Michael Eyong ${ }^{1}$, Chinedu Chukwu² \\ ${ }^{1}$ Department of Obstetrics and Gynecology, University of Calabar Teaching Hospital (UCTH), Calabar, Nigeria \\ ${ }^{2}$ Department of Radiology, University of Calabar Teaching Hospital, Calabar, Nigeria
}

Email address:

newlifecj@yahoo.com (C. I. Emechebe)

${ }^{*}$ Corresponding author

\section{To cite this article:}

Cajethan Ife Emechebe, Charles Obinna Njoku, Jenkins Tobechukwu Ukaga, Edu Michael Eyong, Chinedu Chukwu. Prediction of Birth Weight at Term: Validation of a Clinical Method in a Low Resource Setting. Journal of Gynecology and Obstetrics.

Vol. 4, No. 4, 2016, pp. 19-24. doi: 10.11648/j.jgo.20160404.11

Received: July 25, 2016; Accepted: August 5, 2016; Published: August 29, 2016

\begin{abstract}
Clinical and ultrasound measurement of fetal weight provides a non-invasive and precise way of obtaining information of fetal size. Both low birth weight and macrosomia are associated with increased risk of complications during labor and puerperium. The objective of this study was to determine the accuracy and error in predicting fetal weights in-utero using clinical and ultrasonographic methods of fetal weight estimations. This prospective study was carried out on 200 mothers with singleton term pregnancy admitted for delivery. Accuracy of birth weight estimation was determined by calculating the absolute percentage error and the ratio by percentage of estimate within $10 \%$ of actual birth weight. Result: The mean actual birth weight was 3,242 $\pm 508 \mathrm{~g}$. The mean absolute percentage errors of both clinical and ultrasound methods were $11.16 \% \pm$ 9.48 and $9.036 \% \pm 7.61$ respectively and the difference was not statistically significant $(\mathrm{p}=0.205)$. The accuracy within $10 \%$ of actual birth weights were $69.5 \%$ and $72 \%$ for both clinical estimation of fetal weight and ultrasound respectively and the difference was not statistically significant $(\mathrm{p}=0.755)$. In both normal fetal weight group and macrosomia, no significant difference was observed in their measure of accuracy. However, in the low birth weight group, ultrasound method was better in predicting the actual birth weight. Conclusion: Clinical method (Dare's method) is comparable to Hadlock method of predicting birth weight at term. However, when low birth weight is suspected in low resource areas, ultrasound should be recommended for better prediction of fetal weight.
\end{abstract}

Keywords: Fetal Weight, Ultrasound, Birth Weight, Hadlock Formula, Calabar, Nigeria

\section{Introduction}

Accurate fetal weight estimation is paramount in deciding the obstetric management and the fetal outcome. In the past decades, fetal weight estimation (FWE) relied exclusively on clinical methods based on abdominal palpation and uterine measurements. The estimation of fetal birth weight has advanced from estimation by physical examination to fetal ultrasound using multiple parameters. Since the advent of ultrasound and its dissemination over the last three decades, there has been a widespread belief that ultrasound is more accurate than other methods for predicting fetal weight. Recently, several studies have reported that fetal weight estimation using abdominal palpation were as accurate as ultrasound FEW and with the advantage of being inexpensive and available at any time $[1,2]$.

Both intrauterine growth restriction and macrosomia at delivery are associated with an increased risk of newborn complications during labor and puerperium. The potential complications associated with vaginal delivery of macrosomia include shoulder dystocia, brachial plexus injury, bone injuries and intrapartum asphyxia. While the maternal risks include birth canal and pelvic floor injuries, increased rate of operative vaginal, caesarean deliveries and post partum hemorrhage [3, 4]. Although, some investigators consider sonographic estimates to be superior to clinical 
estimates, others in comparing both techniques concurrently concluded that they confer similar level of accuracy $[5,6]$. In developing countries like Nigeria where about $70 \%$ of deliveries are being undertaken in the rural areas that lacked expensive ultrasound and trained personnel, clinical method of fetal weight estimation may still be valuable for screening pregnant women with abnormal fetal weights. Clinical method of fetal weight estimation (Dare's method) using fundal height and maternal abdominal girth measurements can easily be taught and used especially in rural areas. Also, it can be carried out at no cost, easy to perform especially for less experienced examiners [4, 7].

This study is aimed at resolving these conflicting reports and to determine the more accurate method of fetal weight estimation of the two in our resource constrain environment, thereby improving management of high risk pregnancy.

\section{Methodology}

This prospective cross-sectional comparative study was carried out at the Obstetrics and Gynecology Department of the University of Calabar Teaching Hospital (UCTH), Calabar. Calabar is the capital city of Cross River state southsouth Nigeria with population of 371,022 and the population are predominantly civil servants, traders and farmers [8]. UCTH is a tertiary health facility located in Calabar, southsouth geopolitical area of Nigeria. The participants were mothers with singleton term pregnancy in cephalic presentation, admitted for delivery for various reasons either for normal vaginal delivery, elective caesarean section or induction of labor. The women had their gestational age confirmed by early dating or ultrasound scanning before 22 weeks, booked and managed according to the laid down departmental protocols. Exclusion criteria included unbooked women, polyhydramnios, preterm labor, ruptured membranes, abnormal lie and presentation, multiple pregnancies, antepartum hemorrhage and eclampsia. Others were obvious congenital anomaly, oligohydramnios, uterine fibroids and poor visualization of fetal parts. The study was performed over a 5 months period and the selection was done using systematic random sampling. The participants selected were counseled and after consenting were included in the study. The interval between clinical and ultrasound estimation of fetal weight in-utero and delivery of the babies was within $72 \mathrm{hrs}$ to minimize fetal weight change before delivery. Information on age, last menstrual period, gestational age and parity were obtained from participants and case files before delivery. The maternal weight was determined using adult weighing scale with minimal clothing and recorded. Then in-utero clinical estimations of fetal weight were carried out by only the investigator in the labor ward using the same flexible tape measure calibrated in centimeter. Using this tape, the fundal height was measured from the highest point on the uterine fundus to the mid-point of the upper border of the symphysis pubis while the participant was lying on the dorsal position. Measurement was made using the tape reverse side up so as to forestall any bias. The abdominal circumference was measured at the level of the umbilicus using the same measuring tape at the same dorsal position. The measurements were taken twice and the average obtained to reduce bias. Dare formula (fundal height multiplied by the abdominal circumference in centimeters) was used to calculate the clinical fetal weights in grammes.

After the clinical estimations, the patients had ultrasonographic estimations of fetal weight performed by the investigator under the supervision of a trained radiologist of the radiology department. The biparietal diameter (BPD) was measured from the outer table of the proximal fetal skull and the inner table of the opposite side of the skull at the level of falx cerebri, the thalamus, and carvum septum pellucidum. Head circumference was measured in a plane that is perpendicular to the parietal bones and traverses the third ventricle and thalami. The image demonstrated smooth and symmetrical calvaria and the presence of a cavum septum pellucidum. The calipers were placed on the outer edges of the calvaria and a computer-generated ellipse was adjusted to fit around the fetal head without including the scalp. Femoral length (FL) was a measurement of the largest longitudinal length of the femur not including the femoral head. Abdominal circumference $(\mathrm{AC})$ was measured at the level of the junction of umbilical vein and portal sinus around the fetal abdomen. All the measurements with ultrasound scan were taken twice and average used to reduce bias. Both clinical and ultrasonic estimates were documented into a chart.

After delivery, the birth weights of the babies were determined by weighing of the newborn babies within 30 minutes of delivery employing a standard analogue scale corrected for zero error.

\section{Results}

A total of 200 mothers participated in the study over 5 month's period from May 16, 2013 to October 30, 2013. A total of $36(18.0 \%)$ delivered by caesarean section, while 164(82.0\%) delivered vaginally. The mean actual birth weight was $3,242 \pm 508 \mathrm{~g}$. The low birth weight babies (birth weight $<2,500 \mathrm{~g}$ ) accounted for $12(6.0 \%)$, normal weight babies (birth weight 2,500 to $<4,000 \mathrm{~g}$ ) were $164(82 \%)$, while macrosomia (birth weight $\geq 4,000 \mathrm{~g}$ ) were $24(12.0 \%$ ).

Table 1. The demographic characteristics of the study population.

\begin{tabular}{lll}
\hline Variables & Mean \pm SD & Range \\
\hline Maternal age (years) & $28.86 \pm 6.355$ & $16-44$ \\
Parity & $2.14 \pm 1.737$ & $0-9$ \\
Maternal weight (kg) & $72.48 \pm 11.561$ & $53.0-109.0$ \\
Gestational age at delivery(weeks) & $39.5 \pm 1.513$ & $37-42$ \\
Duration of estimate to delivery (hours) & $47.36 \pm 13.451$ & $4.00-71.00$ \\
Dare's estimate of fetal weight (g) & $3,541 \pm 633 \mathrm{~g}$ & $2,381 \mathrm{~g}-4,924 \mathrm{~g}$ \\
Ultrasound estimate of fetal weight (g) & $3,141 \pm 441 \mathrm{~g}$ & $2,270 \mathrm{~g}-4,590 \mathrm{~g}$ \\
\hline
\end{tabular}

SD-Standard deviation

The mean maternal age was $28.86 \pm 6.355$ years (range, 16 44) years and mean parity was $2.14 \pm 1.737$ (range, 0-9) as shown in table 1 . The mean gestational age was $39.5 \pm 1.513$ weeks (range, 37-42weeks), mean maternal weight was 
$72.48 \pm 11.561 \mathrm{~kg}$ (range, $53-109 \mathrm{~kg}$ ) and the mean time between the fetal weight estimations and delivery was 47.36 \pm 13.451 (range, 4-71) hours.

Table 2 shows the percentage errors and accuracy of both methods over different ranges of birth weights. The mean percentage errors were $9.2 \% \pm 10.44$ and $-3.108 \% \pm 9.67$ for clinical and ultrasound methods respectively and was statistically significant $(\mathrm{P}=0.000)$. This means that in the entire study group, the clinical method significantly overestimated actual birth weight, while the ultrasonic method underestimated it. The mean absolute percentage errors of both clinical and ultrasound methods were $11.16 \% \pm 9.48$ and $9.04 \% \pm 7.61$ respectively. The mean absolute percentage error was smaller for ultrasonic estimation, although the difference was not statistically significant $(P=0.205)$. The correlation coefficient for the clinical and ultrasonic methods, compared to actual birth-weight, were +0.740 and +0.847 respectively, and results of statistical analysis showed the relationships to be statistically significant.

The accuracy within $10 \%$ of actual birth weights were $69.5 \%$ and $72 \%$ for both clinical estimation of fetal weight and ultrasound respectively. The number of ultrasound estimates that were within $10 \%$ of actual birth weight was higher than those of clinical estimates, but the difference was not statistically significant $(\mathrm{P}=0.755)$.

In the low birth weight $(<2,500 \mathrm{~g})$ group, the mean percentage errors were $13.4 \pm 10.62$ and $8.8 \pm 5.30$ for clinical and ultrasound methods respectively and the difference was statistically significant $(\mathrm{P}=0.043)$. The mean absolute percentage errors of both clinical and ultrasound methods were $16.7 \pm 12.98$ and $10.8 \pm 9.46$ respectively and the difference was statistically significant $(\mathrm{P}=0.030)$. This showed that ultrasound method was statistically more accurate with smaller mean errors than those of clinical estimation among the low birth weight group. The accuracy within $10 \%$ of actual birth weights were $51.0 \%$ and $66.0 \%$ for both clinical estimation of fetal weight and ultrasound respectively. The proportion of estimates within $10 \%$ of actual birth weight was higher for the ultrasonic method and was statistically significant $(\mathrm{P}=0.031)$.

In the normal range of fetal birth weight group $(2,500 \mathrm{~g}$ $<4,000 \mathrm{~g}$ ), all the mean errors of ultrasonic estimation were smaller than those of clinical estimation. The mean percentage errors of both clinical and ultrasound methods were $4.5 \% \pm 7.6$ and $-2.8 \pm 8.91$ respectively. The clinical method significantly overestimated birth weight while ultrasound method underestimated birth weights. However, there was no statistically significant difference between the mean absolute percentage errors $(P=0.245)$ and the number of estimates within $10 \%$ of actual birth weight for the two methods $(\mathrm{P}=0.6347)$.

In the macrosomic group $(\geq 4.0 \mathrm{~kg})$, the clinical method systematically overestimated birth-weight, while the ultrasonic method underestimated it. The mean percentage errors were $7.6 \pm 7.1 \%$ and $-4.4 \% \pm 6.3 \%$ for clinical and ultrasound methods respectively. The mean absolute percentage errors of both clinical and ultrasound methods were $11.8 \pm 8.5$ and $9.1 \% \pm 6.8$ respectively. However, the difference in the mean values of the absolute percentage errors was not statistically significant $(\mathrm{P}=0.111)$ and the number of estimates within $10 \%$ of actual birth-weight for the two methods were also not significant $(\mathrm{P}=0.758)$.

Table 2. Shows the percentage errors and accuracy of both methods over different ranges of birth weights.

\begin{tabular}{|c|c|c|c|}
\hline Fetal weight range & $\begin{array}{l}\text { Clinical } \\
\operatorname{method} \pm \text { SD }\end{array}$ & $\begin{array}{l}\text { Ultrasound } \\
\pm \text { SD }\end{array}$ & P-value \\
\hline \multicolumn{4}{|l|}{ Overall fetal weight } \\
\hline Mean percentage error & $9.2 \% \pm 10.44$ & $-3.1 \% \pm 9.67$ & 0.000 \\
\hline Mean absolute percentage error & $\begin{array}{l}11.16 \% \pm \\
9.48\end{array}$ & $9.04 \% \pm 7.61$ & 0.205 \\
\hline $\begin{array}{l}\text { Accuracy within } 10 \% \text { of } A B W \\
<2,500 \mathrm{~g}\end{array}$ & $69.5 \%$ & $72 \%$ & 0.755 \\
\hline Mean percentage error & $13.4 \pm 10.62$ & $8.8 \pm 5.30$ & 0.043 \\
\hline Mean absolute percentage error & $16.7 \pm 12.98$ & $10.8 \pm 9.46$ & 0.030 \\
\hline Accuracy within $10 \%$ & $51.0 \%$ & $66.0 \%$ & 0.031 \\
\hline \multicolumn{4}{|l|}{$2,500-<4,000 \mathrm{~g}$} \\
\hline Mean percentage error & $4.5 \% \pm 7.6$ & $-2.8 \pm 8.91$ & 0.000 \\
\hline Mean absolute percentage error & $9.8 \% \pm 5.62$ & $7.9 \pm 7.64$ & 0.245 \\
\hline $\begin{array}{l}\text { Accuracy within } 10 \% \\
\geq 4,000 \mathrm{~g}\end{array}$ & $71 \%$ & $74 \%$ & 0.635 \\
\hline Mean percentage error & $7.6 \pm 7.1$ & $-4.4 \% \pm 6.3$ & 0.000 \\
\hline Mean absolute percentage error & $11.8 \pm 8.5$ & $9.1 \% \pm 6.8$ & 0.111 \\
\hline Accuracy within $10 \%$ & $69.0 \%$ & $71 \%$ & 0.758 \\
\hline
\end{tabular}

S. D - Standard deviation

Figure 1 Show the chart of overall mean absolute percentage error of each estimated fetal weight by clinical and ultrasound methods. The mean absolute percentage errors of both clinical and ultrasound methods were $11.16 \%$ \pm 9.48 and $9.04 \% \pm 7.61$ respectively.
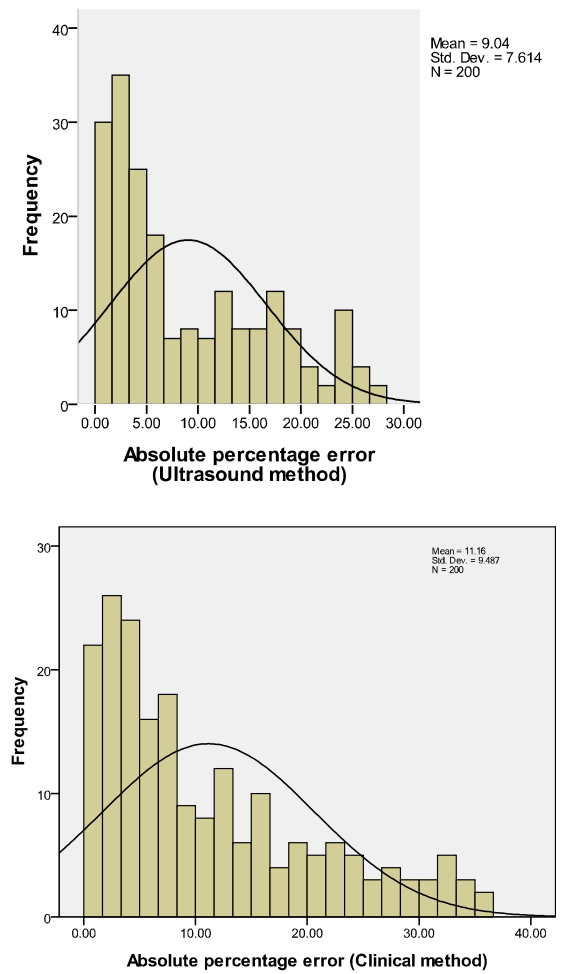

Figure 1. The overall mean absolute percentage error of clinical and ultrasound methods. 
The actual fetal birth weight increased with increase in maternal weight at delivery (table 3 ). The accuracy of both clinical and ultrasound evaluation of fetal weight with different ranges of maternal weight were not statistically significantly different among maternal weight groups of 51-
60 to 91-100. However, the difference in estimated means by both methods was significant when the maternal weight was above $100 \mathrm{~kg}$, with ultrasound being significantly more accurate than clinical method at maternal weight above $100 \mathrm{~kg}(\mathrm{t}$-test $=4.474, \mathrm{P}=0.046)$.

Table 3. Shows the relationship between maternal weight at delivery, mean clinical and ultrasound estimated fetal weight with mean actual fetal birth weights.

\begin{tabular}{|c|c|c|c|c|c|}
\hline Maternal weight (kg) & Mean actual birth weights $( \pm$ S.D) & Mean weights clinical & Mean weights Uss & t-test & P-value \\
\hline $51-60$ & $2,935( \pm 413 \mathrm{~g})$ & $3,082( \pm 543 \mathrm{~g})$ & $2,781( \pm 431 \mathrm{~g})$ & 3.218 & 0.084 \\
\hline $61-70$ & $3,062( \pm 538 \mathrm{~g})$ & $3,201( \pm 543)$ & $2,903( \pm 422 \mathrm{~g})$ & 0.513 & 0.659 \\
\hline $71-80$ & $3,169( \pm 446 \mathrm{~g})$ & $3,199( \pm 589)$ & $3,061( \pm 432 \mathrm{~g})$ & 1.522 & 0.267 \\
\hline $81-90$ & $3,480( \pm 566 \mathrm{~g})$ & $3,625( \pm 602)$ & $3,229( \pm 426 \mathrm{~g})$ & 3.897 & 0.060 \\
\hline $91-100$ & $3,571( \pm 558 \mathrm{~g})$ & $3,791( \pm 699)$ & $3,473( \pm 534 \mathrm{~g})$ & 3.338 & 0.079 \\
\hline$>100$ & $3,694( \pm 425 \mathrm{~g})$ & $3,905( \pm 753)$ & $3,502( \pm 597 \mathrm{~g})$ & 4.474 & 0.046 \\
\hline
\end{tabular}

Uss- ultrasound; S. D- Standard deviation

\section{Discussion}

Birth weight is a key factor in decision making and outcome of fetus. It helps to determine the mode of delivery, predict the fetal outcome hence reducing the maternal and neonatal morbidity. Many studied have been undertaken to find out the accurate methods of estimation of fetal weight. It includes clinical and ultrasound estimations. Clinical method includes models incorporating height of the uterus and girth of the abdomen measured at the level of umbilicus. Estimation of fetal weight is done ultrasonographically using abdominal circumference (AC) alone (Campbell and Wilkin); AC and biparietal diameter (BPD)(Sheppard et al); AC, BPD and femur length (Hadlock et al) $[9,10,11]$. Determination of fetal weight within $10 \%$ of actual birth weight is considered acceptable accuracy [2, 7]. Our study has found that ultrasound has an error of $290 \mathrm{gm}$ in estimating the fetal weight which is almost similar to the other study [1]. The accuracy of both clinical and ultrasound evaluation of fetal weight with different ranges of maternal weights was significantly different when the maternal weight was above $100 \mathrm{~kg}$, with ultrasound being significantly more accurate than clinical method at maternal weight above $100 \mathrm{~kg}$. Both methods performed relatively poorly when the maternal weight was above $100 \mathrm{~kg}$ and the estimations were significantly different from actual birth weight and standard deviations were large. Although, ultrasound scan in obese women has been shown to be less accurate due to poor picture image in ultrasound compared to non-obese women [12], it was even found to be more accurate than the clinical method in this study. One possible explanation is that it may be due to excessive abdominal fats that unduly increased clinical fetal weight calculations. It is possible that maternal adiposity may have a greater impact on fetal weight estimation than originally thought and perhaps the proposed correction factor should be re-evaluated in a larger sample of obese women [13].

The mean percentage errors were $9.2 \% \pm 10.44$ and $3.10 \% \pm 9.67$ for clinical and ultrasound methods respectively. This means that in the entire study group, the clinical method systematically overestimated actual birth weight, while the ultrasonic method underestimated it. The mean absolute percentage errors of both clinical and ultrasound methods were $11.16 \% \pm 9.48$ and $9.04 \% \pm 7.61$ respectively. Shittu et al found that the mean absolute percentage error by clinical and ultrasound methods were $9.7 \%$ and $9.9 \%$ and that the error was higher in ultrasonograghic method though the difference was not statistically significant. In this study, the mean absolute percentage error was lower in ultrasound method though the difference was not statistically significant. The reason may be due to improvement in skills, knowledge of scanning and the quality of ultrasound machine in recent time. These results are also consistent with what have been previously observed that the mean absolute percentage error of predicting birth weight varies from $6 \%$ to $12 \%$ of actual birth-weight, and $40-75 \%$ of the estimates were within $10 \%$ of actual birth-weight $[14,15,16]$. In the large study evaluating the accuracy of fetal weight estimation through clinical palpation in 661 full-term patients, Chauhan et al. reported a mean absolute percentage error of 10.3 percent [17], which was very similar to the value obtained in this study. The overall accuracy within $10 \%$ of actual birth weights were $69.5 \%$ and $72 \%$ for both clinical and ultrasound estimation of fetal weight respectively and the difference was not statistically significant. The finding in this study was comparable to the study by Shittu et al which reported that $70 \%$ and $69 \%$ of estimated fetal weights were within $10 \%$ of actual birth for clinical and ultrasound method respectively and the difference was not statistically significant [6]. The study revealed that clinical estimation of fetal weight is as accurate as the ultrasonographic method of estimation in overall ranges of fetal weight.

However, in cases of intrauterine growth restriction (birthweight $<2,500 \mathrm{~g}$ ), both methods overestimated birth weight in this study. The mean absolute percentage errors of both clinical and ultrasound methods were $16.7 \% \pm 12.98 \%$ and $10.8 \% \pm 9.46 \%$ respectively and the difference was statistically significant. The ultrasonic method was statistically more accurate with smaller mean errors and more estimates within $\pm 10 \%$ of actual birth-weight. Chauhan et al., in their comparison of accuracy of the two methods for low birth weight $(<2,500 \mathrm{~g})$, observed that sonographic estimate was better than the clinical method and that ultrasound yields a better prediction [17]. The role for 
ultrasonographic estimation appears that, when clinically estimated weight suggests weight less than $<2,500 \mathrm{~g}$, subsequent sonographic estimation would yield a better prediction and would be further necessary to assess such fetuses for congenital malformation and to do the biophysical profile to determine the well-being of the fetus.

The difference in accuracy of clinical and ultrasound estimation of fetal weight obtained in normal birth weight range of $2,500-<4,000 \mathrm{~g}$ were not statistically significant. The accuracy of clinical estimation obtained in this study was highest in the birth weight range of $2,500-<4,000 \mathrm{~g}$ and lowest for the low birth weight group $(<2,500 \mathrm{~g})$. This is in consonance with what several investigators have shown that the clinical method is as accurate as ultrasound in estimating fetal weight in the reference birth weight range of 2,500 to $<4,000 \mathrm{~g}[2,6,16]$.

In the macrosomic birth weight $(\geq 4,000 \mathrm{~g})$ group, the clinical method systematically overestimated birth weight, while the ultrasonic method underestimated it. However, the difference in the means of the absolute percentage errors and the number of estimates within $10 \%$ of actual birth weight for the two methods were not statistically significant. The finding was similar to the study in Ile-Ife Nigeria [6]. The overestimation of fetal weights by the clinical method can be viewed as a positive factor since it will enhance the sensitivity of health workers at peripheral centers if properly taught to them for earlier referral of mothers with macrosomic fetuses, thus contributing to reduction in obstructed labor and its sequelae. This observation that ultrasound overestimated low birth weight and underestimated high birth weight when compared to actual birth-weight have also been previously reported [1, 16]. This study confirms the usefulness of clinical estimation of fetal weight.

Johnstone et al found clinical examination to be as predictive as ultrasound measurement in assessing fetal macrosomia in a diabetic population [18]. Chauhanet al., in their comparison of accuracy of the two methods, observed no benefit in obtaining a sonographic estimate because its accuracy is not better than that of the clinical method [17]. The ultrasonographic estimation may play a role when clinically estimated weight suggests weight less than $<2,500$ g, where sonographic estimation would yield a better prediction and would be further necessary to determine the well-being of the fetus. It might be supposed that in clinical practice, accurate knowledge of the fetal weight (especially when it is low or macrosomia) at term would be very useful. It could, for example, aid management either by triggering more intensive monitoring of the labor and delivery, or by allowing the alternative of an elective cesarean section to be considered. In clinical obstetrics, there is a tendency to rely on available technology and ignore clinical judgments.

\section{Conclusion}

Among the cases of low birth weight, both methods overestimated birth weight in this study and the difference between the means was statistically significant. While in the macrosomic weight $(\geq 4,000 \mathrm{~g})$ group, the clinical method overestimated birth weight, while the ultrasonic method underestimated it but the difference in the means of the absolute percentage errors was not statistically significant.

Based on the findings from this study, clinical fetal weight estimation should be taught to all health workers. And it is suggested for use as a routine screening tool for all parturients at term and in labor. In obese women or when clinical fetal weight estimation is suggestive of low birth weight, confirmatory ultrasonographic weight assessment is recommended for final decision making.

The limitation of this study is that the number of babies that weighed less than $2,500 \mathrm{~g}$ and $\geq 4,000 \mathrm{~g}$ were small to make conclusion on the accuracy of fetal weight estimation among these weight groups. Further studies are however, necessary to improve the accuracy of fetal weight among macrosomia, intrauterine growth restriction and obese women with adequate sample size.

\section{References}

[1] Sherman DJ, Arieli S, Torbin J, Siegel G, Gaspi E, Bukovsky I. A. Comparison of clinical and ultrasound estimation of fetal weight. Obstet. Gynaecol. 1998; 9: 212-7.

[2] Watson WJ, Soisson AP, Harlass FE. Estimated weight of the term fetus. Accuracy of ultrasound vs clinical examination. J. Reprod. Med. 1998; 33: 369-71.

[3] Ekele B, Otubu JAM. Maternal and perinatal mortality. In: Textbook of obstetrics and gynecology for medical student. Second edition. Agboola A (ed). Heinemann educational books (Nigeria) plc. 2006; 526-531.

[4] Airede AI. Birth weight of Nigerian newborn infants--a review. West Afr. J. Med. 1995; 14:116-20.

[5] Japareth P, Wihoolphen T. Comparison of the accuracy of fetal weight estimation using clinical and sonographic Methods. J. Med. Assoc. Thai. 2004. 87: 51-7.

[6] Shittu AS, Kuti O, Orji EO. Comparison of clinical and ultrasonographic estimation of fetal weight. Int $\mathrm{J}$ GynaecObstet 2005; 90: 140-141.

[7] Dare FO, Ademowore AS, Ifaturoti OO, Nganwuchu A. The value of symphysiofundal height/abdominal girth measurement in predicting fetal weight. Int. J. Gynaecol. Obstet. 1990; 31: 243-248.

[8] Joseph G. O, Simon O. E, Felix U. A. The population situation in Cross River state of Nigeria and its implication for socioeconomic development: Observation from the 1991 and 2006 censuses. Journal of emerging trends in educational research and policy studies (JETERAPS) 2010; 1: 36-42.

[9] Johnson R. W, Toshach C. E. Estimation of fetal weight using longitudinal mensuration. Am. J. Obstet Gynecol.1954; 68: 891-6.

[10] Joseph WSK. A short history of development of Ultrasound in Obstetrics and Gynecology. 1998-2002. Available at http://www.ob-ultrasound.net/history1.html. Last revised November, 2006. 
[11] Colman A, Maharaj D, Hutton J, Juohy J. Reliability of Ultrasound estimation of fetal weight in term singleton Pregnancy. New Zealand med. J. 2006; 119:124-8.

[12] Klufio C. A. Obesity in pregnancy. In: Comprehensive obstetrics in the tropics. Kwawukume E. Y and Emuveyan EE (Eds). Asante and Hittscher printing press Dansoman (Ghana) 2002; 1: 219-5.

[13] Maria R. T, Nelson S, Jussara L. S, Ana Carolina P. R, Maísa F, Paula R. L. Clinical formulas, mother's opinion and ultrasound in predicting birth weight. Sao Paulo Med J. 2008; 126: $145-9$.

[14] Baum JD, Gussman D, Wirth JC. Clinical estimation of fetal weight vs ultrasound estimation. J. Reprod. Med (united states). 2002; 47:194-8.
[15] Ratanasiri T, Jimpornkul S, Sombooporn W. Comparison of the accuracy of ultrasound fetal weight estimation by using the various equations. J med. Assoc Thai (Thailand), 2002; 85: 962-7.

[16] Banerjee K, Mittal S, Kumar S. Clinical vs. ultrasound evaluation of fetal weight. Int J Gynaecol Obstet. 2004; 86: 41-3.

[17] Chauhan SP, Hendrix NW, Magann EF, Morrison J.C, Jenney S. P, Devoe L. D. Limitations of clinical and sonographic estimates of birth weight: experience with 1034 parturients. ObstetGynecol1998; 91: 72-7.

[18] Johnstone FD, Prescott RJ, Steel JM, Mao JH, Chambers S, Muir N. Clinical and ultrasound prediction of macrosomia in diabetic pregnancy. Br J ObstetGynaecol 1996; 103: 747-54. 